\title{
CORRIGENDA
}

\section{Corrigendum: Comparison of the SIMARD MD to clinical impression in assessing fitness to drive in patients with cognitive impairment}

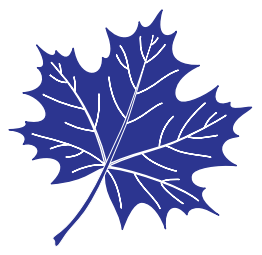

Madelaine Wernham, BNSc${ }^{1}$, Pamela G. Jarrett, MD, FRCPC, FACP ${ }^{2}$, Connie Stewart, $\mathrm{PhD}^{3}$, Elizabeth MacDonald, MD, FRCPC ${ }^{2}$, Donna MacNeil, PhD, MD, FRCPC ${ }^{2}$, Cynthia Hobbs, MD, FRPC ${ }^{2}$

${ }^{1}$ Dalhousie University Medical School, Saint John, NB; ${ }^{2}$ Department of Medicine, Dalhousie University, Saint John, NB, Department of Medicine, Memorial University, St. John's, NL, and Horizon Health Network, Saint John, NB;

${ }^{3}$ Department of Computer Science \& Applied Statistics, University of New Brunswick, Saint John, NB

DOI:http://dx.doi.org/10.5770/cgj.18.200

\section{Original Citation}

Canadian Geriatrics Journal, Volume 17, Number 2, June 2014. DOI:http://dx.doi.org/10.5770/cgj.17.100

\section{Description of error:}

Below Table 2, the p-value was reported as 0.037 . The correct p-value is 0.073 , as described in the text of the Results section. 